\title{
The effect of tobacco control policies on smoking prevalence and smoking-attributable deaths. Findings from the Netherlands SimSmoke Tobacco Control Policy Simulation Model
}

Citation for published version (APA):

Nagelhout, G. E., Levy, D. T., Blackman, K., Currie, L., Clancy, L., \& Willemsen, M. C. (2012). The effect of tobacco control policies on smoking prevalence and smoking-attributable deaths. Findings from the Netherlands SimSmoke Tobacco Control Policy Simulation Model. Addiction, 107(2), 407-416. https://doi.org/10.1111/j.1360-0443.2011.03642.x

Document status and date:

Published: 01/02/2012

DOI:

10.1111/j.1360-0443.2011.03642.x

Document Version:

Publisher's PDF, also known as Version of record

Document license:

Taverne

Please check the document version of this publication:

- A submitted manuscript is the version of the article upon submission and before peer-review. There can be important differences between the submitted version and the official published version of record. People interested in the research are advised to contact the author for the final version of the publication, or visit the DOI to the publisher's website.

- The final author version and the galley proof are versions of the publication after peer review.

- The final published version features the final layout of the paper including the volume, issue and page numbers.

Link to publication

\footnotetext{
General rights rights.

- You may freely distribute the URL identifying the publication in the public portal. please follow below link for the End User Agreement:

www.umlib.nl/taverne-license

Take down policy

If you believe that this document breaches copyright please contact us at:

repository@maastrichtuniversity.nl

providing details and we will investigate your claim.
}

Copyright and moral rights for the publications made accessible in the public portal are retained by the authors and/or other copyright owners and it is a condition of accessing publications that users recognise and abide by the legal requirements associated with these

- Users may download and print one copy of any publication from the public portal for the purpose of private study or research.

- You may not further distribute the material or use it for any profit-making activity or commercial gain

If the publication is distributed under the terms of Article $25 \mathrm{fa}$ of the Dutch Copyright Act, indicated by the "Taverne" license above,

Download date: 26 Apr. 2023 


\title{
The effect of tobacco control policies on smoking prevalence and smoking-attributable deaths. Findings from the Netherlands SimSmoke Tobacco Control Policy Simulation Model
}

\author{
Gera E. Nagelhout ${ }^{1,2}$, David T. Levy ${ }^{3}$, Kenneth Blackman ${ }^{3}$, Laura Currie ${ }^{4,5}$, Luke Clancy ${ }^{4}$ \& \\ Marc C. Willemsen ${ }^{1,2}$
}

Maastricht University (CAPHRI), Maastricht, the Netherlands,' STIVORO Dutch Expert Centre on Tobacco Control,The Hague, the Netherlands, ${ }^{2}$ Pacific Institute for Research and Evaluation, Baltimore, MD, USA, ${ }^{3}$ TobaccoFree Research Institute, Dublin, Ireland ${ }^{4}$ and Royal College of Surgeons, Dublin, Ireland ${ }^{5}$

\section{ABSTRACT}

Aim To develop a simulation model projecting the effect of tobacco control policies in the Netherlands on smoking prevalence and smoking-attributable deaths. Design, setting and participants Netherlands SimSmoke-an adapted version of the SimSmoke simulation model of tobacco control policy - uses population, smoking rates and tobacco control policy data for the Netherlands to predict the effect of seven types of policies: taxes, smoke-free legislation, mass media, advertising bans, health warnings, cessation treatment and youth access policies. Measurements Outcome measures were smoking prevalence and smoking-attributable deaths. Findings With a comprehensive set of policies, as recommended by MPOWER, smoking prevalence can be decreased by as much as $21 \%$ in the first year, increasing to a $35 \%$ reduction in the next 20 years and almost $40 \%$ by 30 years. By 2040, 7706 deaths can be averted in that year alone with the stronger set of policies. Without effective tobacco control policies, almost a million lives will be lost to tobacco-related diseases between 2011 and 2040. Of those, 145000 can be saved with a comprehensive tobacco control package. Conclusions Smoking prevalence and smoking-attributable deaths in the Netherlands can be reduced substantially through tax increases, smoke-free legislation, high-intensity media campaigns, stronger advertising bans and health warnings, comprehensive cessation treatment and youth access laws. The implementation of these FCTC/MPOWER recommended policies could be expected to show similar or even larger relative reductions in smoking prevalence in other countries which currently have weak policies.

Keywords Prevalence rates, public policy, simulation model, smoking-attributable deaths, the Netherlands, tobacco control policy.

Correspondence to: Gera E. Nagelhout, STIVORO Dutch Expert Centre on Tobacco Control, PO Box 16070, 2500 BB The Hague, the Netherlands.

\section{INTRODUCTION}

Globally, it is estimated that 5 million premature deaths each year are attributable to smoking, with trends driving a rise to 10 million deaths per year by the 2030s [1]. Substantial evidence indicates that higher cigarette taxes, smoke-free legislation, advertising bans and wellfunded media campaigns can reduce adult smoking rates appreciably, especially when combined as a comprehensive strategy [2,3]. Evidence is mounting for health warnings [4] and cessation treatment coverage [5].
The World Health Organization (WHO) has set out the Framework Convention on Tobacco Control (FCTC). The MPOWER Report [6] has defined a set of policies that are consistent with the FCTC. MPOWER suggests that each nation impose taxes on cigarettes that constitute at least $70 \%$ of the retail price, require large, bold and graphic health warnings, provide broad access to cessation treatments, conduct a well-funded mass media campaign and implement and enforce comprehensive smoke-free legislation and advertising restrictions. 
The Netherlands ratified the FCTC in January 2005. Since 2000, the Netherlands has increased taxes on cigarettes, strengthened advertising restrictions and health warnings on cigarette packs, implemented smoke-free legislation and mass media campaigns and offered a quitline. Although considerable progress has been made, Dutch tobacco control policies are not compliant with WHO guidelines. For example, taxes on cigarettes are $57 \%$ of the retail price in the Netherlands $[6,7]$ rather than the $70 \%$ recommended by MPOWER guidelines. Also, the Dutch smoke-free legislation does not apply to all bars and allows for designated smoking rooms in all workplaces. This study uses a simulation model to examine the effect of Dutch policies implemented since 1996 and to predict the effect of implementing stricter policies fully consistent with WHO guidelines.

Most statistical studies of tobacco control policies have examined the effect of only one or, at most, two policies (e.g. [8-10]) because the ability to untangle the effects of tobacco control policies on smoking rates is often limited by a lack of data or models that cannot statistically distinguish the effects. Simulation models combine information from different sources to provide a useful tool for examining how the effects of public policies unfold over time in complex social systems [11,12]. Simulation models examining the effect of tobacco control policies have been developed by Mendez \& Warner [13,14], Tengs et al. [15,16], Ahmad [17,18] and Levy et al. [12,16,19]. In the Netherlands, the chronic disease model has been used to examine the impact of tobacco control policies on smoking rates and health risks, but has not modelled the full set of MPOWER interventions [20,21]. The SimSmoke model of Levy et al. simultaneously considers a broader array of public policies than other models [22] and has been validated in several countries $[23,24]$ and states [25, 26, 27].

In order to examine past trends in smoking rates and the potential effect of tobacco control policies on future smoking rates, a modified version of SimSmoke has been developed for the Netherlands. The Netherlands is an interesting case, because Dutch tobacco control policy has seen a marked improvement between 2000 and 2004 , followed by a long period of stagnation. This provides a good setting to demonstrate the ability of the SimSmoke model to do two things: to calculate the impact of real policy changes and to examine what could potentially be accomplished with full implementation of MPOWER policies. The Netherlands has strong tobacco control policies relative to many of the other high-income countries [28].

Using data from the Netherlands on population, birth rates, death rates and smoking rates, the model predicts future smoking rates. Using data on relative mortality risks, the model also estimates the number of smoking- attributable deaths (SADs). Netherlands SimSmoke shows the effect of policies implemented since 1996. The model also assesses the effect of MPOWER interventions and youth access restrictions. The following research questions are examined in this study:

1 What would have been the smoking prevalence and SADs in 2010 if tobacco control policies had remained unchanged from their 1996 levels?

2 What were the effects of tobacco control policies implemented between 1996 and 2010 on smoking prevalence and SADs in 2010?

3 What will be the smoking prevalence and SADs in 2040 if tobacco control policies remain unchanged from their 2010 levels?

4 What would be the effects of MPOWER policies implemented in 2011 on smoking prevalence and SADs in 2040?

\section{METHODS}

\section{Basic model}

SimSmoke includes a population model, a smoking model, a smoking-attributable death model and policy modules [12,19]. The model begins in a baseline year, with the population divided into smokers, never smokers and previous smokers by age and gender. The baseline year for the Netherlands model was chosen as 1996 because a large survey was conducted at that time and major policy changes had not yet been implemented.

A discrete time, first-order Markov process is employed to project future population growth through fertility and deaths, and to project smoking rates. Individuals are classified as never smokers from birth until they initiate smoking or die. They may evolve from current to former smoker through cessation or may return to smoker through relapse. The extent of relapse depends on the number of years since quitting. Smoking rates, and thereby smoking-attributable deaths, change over time in response to changes in tobacco control policies.

\section{Population model}

Population (1996), mortality (1999) and fertility (2008) data by age and gender were obtained from Statistics Netherlands (CBS). Population projections from the model for 2010 were close to 2010 estimates.

\section{Smoking model}

The 1996 data from the Dutch Continuous Survey of Smoking Habits (DCSSH) was used to obtain smoking prevalence and cessation rates. This is a cross-sectional population survey of respondents aged 15 years and older that is used to monitor smoking habits of the Dutch 
population, using weekly measurements [29]. The DCSSH is conducted by TNS NIPO for the Dutch expert centre on tobacco control (STIVORO). Data on smoking prevalence from the DCSSH were available for each year from 1988 to 2010 by gender and age group. The interviewing method changed in 2001 from face-to-face to web surveying and the sampling method changed in 2009 from household to person-based sampling.

Net initiation rates at each age to age 30 years were measured as the difference between the smoking rate at that age year and the rate at the previous age year. Cessation rates were measured after age 30 as the number of ex-smokers who quit in the last year divided by the number of those smoking 1 year ago (current smokers plus those quitting in the last year). US relapse rates were used because data were not available for the Netherlands, but the rates were calibrated to the model.

\section{SAD model}

SADs by age, gender and smoking status were calculated from death rates, smoking rates and relative risks. The number of current and former smokers at each age was multiplied by their respective excess risk and summed to obtain total SADs.

Large-scale studies of the relative risk of smoking were not available for the Netherlands. However, because the Netherlands has a similar smoking history to the United States and is a high-income country, we used relative risk estimates from the US Cancer Prevention Study II [30] and other high-income countries [31].

\section{Policy modules}

Policy effect sizes are in terms of percentage reductions applied to smoking prevalence in the year when a policy is implemented and, unless specified otherwise, applied to initiation and cessation rates in future years. The effect sizes are shown relative to the absence of any policy. They are based on literature reviews, advice of an expert panel and previous model validation. As a high-income country, the effects for the Netherlands were determined primarily from studies for that country and other highincome countries. Policies and potential effect sizes in the Netherlands are summarized in Table 1.

\section{Analyses}

The model estimates the effects over time for two primary outcomes: smoking prevalence and SADs. The model estimates these outcomes for the tracking period, from 1996 to 2010, and projects future outcomes for 2011 to 2040.

Based on comparing the actual to the predicted smoking prevalence rates from 1996 to 2000, we cali- brated the model by adjusting the first-year cessation rates downwards, increasing the relapse rate of first-year cessation from $50 \%$ to $65 \%$ for males and females, and also modifying the rates to $40 \%$ at ages above 65 . To validate the model, we compared the predicted smoking rates overall and by gender and age to annual smoking rates by age and gender from the yearly DCSSH. More information about the model validation can be found in the full Netherlands SimSmoke report [32].

The effect of past policies from 1996 to 2010 was examined relative to a counterfactual scenario, where no tobacco control policies are implemented. In the model, we set policies through 2010 to their levels in 1996. The difference between the smoking rate and SADs with policies held constant at their 1996 levels and with the actual policies in place yields the net effect of policies implemented since 1996. For the role of single policies, we compared the scenario with only that policy implemented (in the year in which it was implemented) to the no policy scenario.

Furthermore, the effect of implementing MPOWER policies in 2011 was examined relative to the status quo scenario, where tobacco control policies were maintained at their 2010 level. For SADs, we calculated deaths averted as the difference between the number of deaths under the new policy and the number of deaths under the status quo.

\section{RESULTS}

\section{Smoking prevalence from 1996 to 2010}

Between 1996 and 2010, the model predicted that male smoking rates would decrease from $38.4 \%$ to $29.0 \%$ (a $24.5 \%$ decrease in relative terms) and that female smoking rates would decrease from $29.6 \%$ to $24.5 \%$ (a $17.2 \%$ relative decline). The male and female models generally tracked well with annual data on smoking prevalence (for more details, see [32]). The model slightly under-predicted the actual reduction in smoking prevalence, which is a relative decline of $26.9 \%$ for males and $17.7 \%$ for females. The model is most accurate in the 25-64-year age range.

\section{Past policy tracking from 1996 to 2010}

When tobacco control policies were held constant at their 1996 levels, smoking prevalence decreased from $34.5 \%$ in 1996 , to $33.9 \%$ in 2000 and to $32.1 \%$ in 2010 (Table 2). Compared to the level with policies (27.0\% by 2010), smoking prevalence has been reduced by $16 \%$. SADs increased from 30193 in 1996 to 33502 in 2010 and would have been 465031 in total over all years from 1996 to 2010. Compared to the 
Table 1 Policies, description and effect sizes of the SimSmoke model and policies in the Netherlands.

\begin{tabular}{lll}
\hline Policy & Description & Potential percentage effect* \\
\hline Tax policy & & \\
Tax policy & Cigarette price index adjusted for & Through price elasticity: \\
& inflation for 2000-10, future & -0.3 ages $15-17$ \\
& prices increase with the & -0.2 age $18-24$ \\
& amount of the cigarette tax in & -0.15 ages $25-34$ \\
& absolute terms & -0.1 ages 35 and above
\end{tabular}

Policies in the Netherlands

Tax policy

absolute terms

Prices were relatively constant from 1996 through 2003, then increased in 2004, 2007 and 2009. After correcting for inflation, prices have risen by about $70 \%$ since 1996 . The specific taxes on cigarettes were $57 \%$ of the retail price by 2008 to 2010

\section{Smoke-free legislation \\ Worksite total ban \\ Worksite ban limited \\ to common area \\ Restaurant and bar total ban \\ Restaurant restricted \\ Other places total ban \\ Enforcement and publicity}

Ban in all areas

Smoking limited to non ventilated common area

Ban in all indoor restaurants in all areas

Limited in restaurants to designated areas

Ban in 3 of 4 (malls, retail stores, public transportation and elevators)

Government agency is designated to enforce and publicize the laws

\section{Mass media campaigns}

Highly publicized campaign

\section{Moderately \\ publicized \\ campaign \\ Low publicity \\ campaign}

\section{Marketing bans \\ Comprehensive} marketing ban
Moderate marketing ban
Weak marketing ban
Enforcement and publicity

Ban is applied all media

\author{
Campaign publicized heavily $\quad 6.5 \%$ effect \\ with funding of \$1US per \\ capita \\ Campaign publicized sporadically \\ with funding of $\$ 0.10$ per \\ capita \\ Campaign publicized only \\ sporadically in newspaper, \\ billboard or some other media \\ $3.6 \%$ effect \\ $1 \%$ effect
}

Ban is applied television, radio, print, billboard, in-store displays, sponsorships and free samples television, radio, print, billboard

Ban is applied some of television, radio, print, billboard

Government agency is designated to enforce the laws
$6 \%$ with variations by age and gender

$2 \%$ with variations by age and gender

$3 \%$ effect

$1 \%$ effect

$1 \%$ effect

Effects reduced by as much as $50 \%$ if no enforcement and no media campaign

$5 \%$ reduction in prevalence, $6 \%$ reduction in initiation, 3\% increase in cessation rates

$3 \%$ reduction in prevalence, $4 \%$ reduction in initiation, $2 \%$

increase in cessation rates

$1 \%$ reduction in prevalence and initiation only

Effects reduced by as much as $50 \%$ if no enforcement
In 2004, a partial smoke-free workplace law came into effect. A ban in bars and restaurants and other public places was implemented in 2008, but left loopholes for small establishments and is set equal to $50 \%$. The enforcement level was set to 5

Tobacco control campaigns have been designated as low intensity before 2000 and medium intensity since 2000

Marketing is considered a weak ban from 1996 increasing to a $50 \%$ of a moderate ban in 2003, 100\% moderate ban in 2008. The enforcement level was set to 5 
Table 1 Cont

\begin{tabular}{|c|c|c|c|}
\hline Policy & Description & Potential percentage effect* & Policies in the Netherlands \\
\hline \multicolumn{4}{|l|}{ Health warnings } \\
\hline Strong & $\begin{array}{l}\text { Labels are large, bold and } \\
\text { graphic }\end{array}$ & $\begin{array}{l}2 \% \text { reduction in prevalence, } 1 \% \\
\text { reduction in initiation and } \\
4 \% \text { increase in cessation rate }\end{array}$ & $\begin{array}{l}\text { Health warnings are considered } \\
\text { to increase from low to } 2001 \text {, } \\
\text { to moderate in } 2002 \text { and }\end{array}$ \\
\hline Moderate & $\begin{array}{l}\text { Warning covers at least } 1 / 3 \text { of } \\
\text { both sides of package, not bold } \\
\text { or graphic }\end{array}$ & $\begin{array}{l}1 \% \text { reduction in prevalence, } \\
0.5 \% \text { reduction in initiation } \\
\text { and } 2.5 \% \text { increase in } \\
\text { cessation }\end{array}$ & remaining at that level \\
\hline Weak & $\begin{array}{l}\text { Warning covers less than } 1 / 3 \text { of } \\
\text { package, not bold or graphic }\end{array}$ & $\begin{array}{l}1 \% \text { reduction in prevalence and } \\
\text { initiation rates, } 1 \% \text { increase } \\
\text { in cessation rate }\end{array}$ & \\
\hline Publicity & $\begin{array}{l}\text { Health information is well } \\
\text { publicized }\end{array}$ & $\begin{array}{l}1 \% \text { additional effect on } \\
\text { prevalence and initiation } \\
\text { rate }\end{array}$ & \\
\hline \multicolumn{4}{|c|}{ Cessation treatment policy } \\
\hline $\begin{array}{l}\text { Cessation treatment } \\
\text { policy }\end{array}$ & $\begin{array}{l}\text { Complete availability and } \\
\text { reimbursement of pharmaco- } \\
\text { and behavioural treatments, } \\
\text { quitlines and brief } \\
\text { interventions }\end{array}$ & $\begin{array}{l}4.75 \% \text { reduction in prevalence, } \\
39 \% \text { increase in cessation } \\
\text { rate }\end{array}$ & $\begin{array}{l}\text { The Netherlands has had } \\
\text { nicotine replacement therapy } \\
\text { available in pharmacies and } \\
\text { buproprion by prescription } \\
\text { since 2001, a quitline since } \\
\text { 2000, and cessation } \\
\text { treatment from some } \\
\text { health-care providers since } \\
1996\end{array}$ \\
\hline \multicolumn{4}{|c|}{ Youth access restrictions } \\
\hline $\begin{array}{l}\text { Strongly enforced } \\
\text { and publicized }\end{array}$ & $\begin{array}{l}\text { Compliance checks are } \\
\text { conducted regularly, penalties } \\
\text { are heavy, and with publicity } \\
\text { is strong, vending machine } \\
\text { and self-service bans }\end{array}$ & $\begin{array}{l}30 \% \text { reduction for age }<16 \text { in } \\
\text { prevalence and initiation } \\
\text { only, } 20 \% \text { reduction for ages } \\
16-17 \text { in prevalence and } \\
\text { initiation only }\end{array}$ & $\begin{array}{l}\text { The Netherlands has had a ban } \\
\text { on the purchase of tobacco by } \\
\text { youth under } 18 \text { years of age } \\
\text { since } 2003 \text {. However, } \\
\text { enforcement has been set at a }\end{array}$ \\
\hline Well enforced & $\begin{array}{l}\text { Compliance checks are } \\
\text { conducted sporadically, } \\
\text { penalties are potent, and little } \\
\text { publicity }\end{array}$ & $\begin{array}{l}15 \% \text { reduction for age }<16 \text { in } \\
\text { prevalence and initiation } \\
\text { only, } 10 \% \text { reduction for ages } \\
16-17 \text { in prevalence and } \\
\text { initiation only }\end{array}$ & $\begin{array}{l}\text { low level since } 2003 \text {, with no } \\
\text { vending machine and } \\
\text { self-service bans }\end{array}$ \\
\hline Low enforcement & $\begin{array}{l}\text { Compliance checks are not } \\
\text { conducted, penalties are weak, } \\
\text { and no publicity }\end{array}$ & $\begin{array}{l}3 \% \text { reduction for age }<16 \text { in } \\
\text { prevalence and initiation } \\
\text { only, } 2 \% \text { reduction for ages } \\
16-17 \text { in prevalence and } \\
\text { initiation only }\end{array}$ & \\
\hline
\end{tabular}

*Unless otherwise specified, the same percentage effect is applied as a percentage reduction in the prevalence and initiation rate and a percentage increase in the cessation rate, and is applied to all ages and both genders. The effect sizes are shown relative to the absence of any policy.

status quo 1996 scenario, 7078 deaths were averted from 1996 to 2010 .

We considered the effects of individual policies at the levels at which they were implemented in the Netherlands between 1996 and 2010. The Dutch tax policy had the largest effect on smoking prevalence by 2010 (reducing prevalence by 9\%), followed by smoke-free legislation (reducing prevalence by $2 \%$ ) (Table 2). However, mass media campaigns had the largest effect on smoking prevalence by 2000. If only the tax policy had been implemented, SADs would have increased to 29925 in 2000 and to 32736 in 2010 and would have totalled 461933 between 1996 and 2010. Therefore, 3098 deaths were averted due to the tax policy. Due to the mass media campaigns, 1217 deaths were averted, and due to the cessation treatment policy 1113 deaths were averted. The other policies averted between 0 (youth access restrictions) and 
Table 2 Tracking the effect of past policies using SimSmoke on smoking prevalence for ages 18 and above and total smokingattributable deaths, the Netherlands, 1996-2010.

\begin{tabular}{|c|c|c|c|c|}
\hline & 1996 & 2000 & 2010 & Cumulative \\
\hline \multicolumn{5}{|l|}{ Smoking prevalence } \\
\hline Status quo 1996 & $34.5 \%$ & $33.9 \%$ & $32.1 \%$ & \\
\hline Tax policy & $34.5 \%$ & $33.6 \%$ & $29.2 \%$ & \\
\hline Smoke-free legislation & $34.5 \%$ & $33.9 \%$ & $31.4 \%$ & \\
\hline Advertising ban & $34.5 \%$ & $33.9 \%$ & $31.8 \%$ & \\
\hline Mass media campaigns & $34.5 \%$ & $33.5 \%$ & $31.6 \%$ & \\
\hline Health warnings & $34.5 \%$ & $33.9 \%$ & $31.8 \%$ & \\
\hline Youth access restrictions & $34.5 \%$ & $33.9 \%$ & $32.1 \%$ & \\
\hline Cessation treatment policy & $34.5 \%$ & $33.9 \%$ & $31.6 \%$ & \\
\hline All above policies combined & $34.5 \%$ & $33.2 \%$ & $27.0 \%$ & \\
\hline \multicolumn{5}{|l|}{ Smoking-attributable deaths } \\
\hline Status quo 1996 & 30193 & 29948 & 33502 & 465031 \\
\hline Tax policy & 30193 & 29925 & 32736 & 461933 \\
\hline Smoke-free legislation & 30193 & 29948 & 33273 & 464379 \\
\hline Advertising ban & 30193 & 29948 & 33397 & 464619 \\
\hline Mass media campaigns & 30193 & 29948 & 33319 & 463814 \\
\hline Health warnings & 30193 & 29948 & 33387 & 464493 \\
\hline Youth access restrictions & 30193 & 29948 & 33502 & 465031 \\
\hline Cessation treatment policy & 30193 & 29948 & 33284 & 463918 \\
\hline All above policies combined & 30193 & 29925 & 31888 & 457953 \\
\hline
\end{tabular}

652 (smoke-free legislation) deaths between 1996 and 2010.

\section{Future policy projections from 2010 to 2040}

If tobacco control policies remain unchanged from their 2010 levels, as in the status quo scenario, male adult smoking is projected to decrease from $29.6 \%$ to $26.7 \%$ from 2010 to 2020 , to $24.6 \%$ by 2030 and to $23.1 \%$ by 2040 (Table 3). In the status quo scenario, female adult smoking prevalence is projected to decrease from $24.9 \%$ in 2010 to $23.5 \%$ by 2020 and to $20.9 \%$ by 2040 (Table 4). As seen in Table 5, the estimated number of SADs in 2010 is 31888 (21 990 for males and 9898 for females). Male SADs are projected to reach their highest point in 2024 and female SADs to reach their highest point in 2034. The total number of SADs is projected to rise to 33013 by 2040. From 2010 to 2040, the cumulative SADs are projected to be 1042836 in the status quo scenario.

When taxes are increased to $70 \%$ of the retail price, smoking rates are projected to decrease to $19.8 \%$ for males (Table 3) and $18.0 \%$ for females (Table 4) by 2040. Summing over years from 2011 to 2040, 40839 deaths will be averted by increased taxes by 2040 (Table 5). Increasing taxes to $70 \%$ of the retail price has the largest effect on smoking prevalence and SADs of all MPOWER policies.

A complete ban on smoking in worksites, bars, restaurants and other public places, along with strong enforce- ment, is predicted to decrease smoking prevalence to $21.8 \%$ for males and $19.7 \%$ for females by 2040 . In total, 27278 deaths will be averted by 2040 .

A comprehensive marketing ban, directed at all promotions as well as media advertising and having strong enforcement, will decrease smoking to $22.1 \%$ for males and 19.9\% for females by 2040. By 2040, 21104 deaths will be averted with a comprehensive marketing ban.

We considered a well-funded tobacco control campaign directed at all smokers relative to the current policy of a medium-intensity campaign. The model predicts a decrease in smoking prevalence to $22.0 \%$ in males and $19.9 \%$ in females by 2040 , with 23293 deaths averted by 2040 .

Implementing graphic health warnings consistent with MPOWER recommendations is projected to have the smallest impact on smoking prevalence. Smoking prevalence is projected to decrease to $22.9 \%$ for males and $20.6 \%$ for females by 2040 , and 4051 deaths will be averted.

With the enforcement of youth access laws, the model predicts a decrease in smoking prevalence to $21.2 \%$ for males and $19.2 \%$ for females by 2040 . Youth access laws have the lowest impact on SADs. From 2010 to 2040, 603 deaths are projected to be averted.

The MPOWER combination of ready availability of nicotine replacement therapy and buproprion, the provision of quitlines and the provision of cessation treatment is projected to reduce smoking prevalence to $21.6 \%$ in 
Table 3 SimSmoke projections: male smoking prevalence for ages 18 and above, the Netherlands, 2010-2040.

\begin{tabular}{|c|c|c|c|c|c|}
\hline & 2010 & 2011 & 2020 & 2030 & 2040 \\
\hline Status quo policies & $29.6 \%$ & $29.3 \%$ & $26.7 \%$ & $24.6 \%$ & $23.1 \%$ \\
\hline \multicolumn{6}{|l|}{ Independent policy effects } \\
\hline Tax at $70 \%$ of retail price & $29.6 \%$ & $26.9 \%$ & $24.0 \%$ & $21.5 \%$ & $19.8 \%$ \\
\hline Complete smoke-free air law & $29.6 \%$ & $28.0 \%$ & $25.5 \%$ & $23.4 \%$ & $21.8 \%$ \\
\hline Comprehensive marketing ban & $29.6 \%$ & $28.3 \%$ & $25.7 \%$ & $23.6 \%$ & $22.1 \%$ \\
\hline High-intensity tobacco control campaign & $29.6 \%$ & $28.3 \%$ & $25.7 \%$ & $23.5 \%$ & $22.0 \%$ \\
\hline Strong health warnings & $29.6 \%$ & $29.2 \%$ & $26.6 \%$ & $24.4 \%$ & $22.9 \%$ \\
\hline Strong youth access enforcement & $29.6 \%$ & $29.3 \%$ & $26.0 \%$ & $23.2 \%$ & $21.2 \%$ \\
\hline Cessation treatment policies & $29.6 \%$ & $28.5 \%$ & $25.4 \%$ & $23.1 \%$ & $21.6 \%$ \\
\hline \multicolumn{6}{|l|}{ Combined policy effects } \\
\hline All above policies combined & $29.6 \%$ & $23.2 \%$ & $19.0 \%$ & $16.0 \%$ & $14.0 \%$ \\
\hline \multicolumn{6}{|c|}{$\%$ Change in smoking prevalence from status quo } \\
\hline \multicolumn{6}{|l|}{ Independent policy effects } \\
\hline Tax at $70 \%$ of retail price & & $-8.3 \%$ & $-10.3 \%$ & $-12.5 \%$ & $-14.5 \%$ \\
\hline Complete smoke-free air law & & $-4.3 \%$ & $-4.7 \%$ & $-5.1 \%$ & $-5.5 \%$ \\
\hline Comprehensive marketing ban & & $-3.5 \%$ & $-3.8 \%$ & $-4.2 \%$ & $-4.5 \%$ \\
\hline High-intensity tobacco control campaign & & $-3.5 \%$ & $-4.0 \%$ & $-4.4 \%$ & $-4.8 \%$ \\
\hline Strong health warnings & & $-0.2 \%$ & $-0.6 \%$ & $-0.9 \%$ & $-1.0 \%$ \\
\hline Strong youth access enforcement & & $0.0 \%$ & $-2.7 \%$ & $-5.6 \%$ & $-8.2 \%$ \\
\hline Cessation treatment policies & & $-2.6 \%$ & $-5.2 \%$ & $-6.2 \%$ & $-6.6 \%$ \\
\hline \multicolumn{6}{|l|}{ Combined policy effects } \\
\hline All above policies combined & & $-20.8 \%$ & $-28.8 \%$ & $-35.0 \%$ & $-39.5 \%$ \\
\hline
\end{tabular}

Table 4 SimSmoke projections: female smoking prevalence for ages 18 and above, the Netherlands, 2010-40.

\begin{tabular}{|c|c|c|c|c|c|}
\hline & 2010 & 2011 & 2020 & 2030 & 2040 \\
\hline Status quo policies & $24.9 \%$ & $24.8 \%$ & $23.5 \%$ & $22.1 \%$ & $20.9 \%$ \\
\hline \multicolumn{6}{|l|}{ Independent policy effects } \\
\hline Tax at $70 \%$ of retail price & $24.9 \%$ & $22.8 \%$ & $21.1 \%$ & $19.5 \%$ & $18.0 \%$ \\
\hline Complete smoke-free air law & $24.9 \%$ & $23.7 \%$ & $22.4 \%$ & $21.0 \%$ & $19.7 \%$ \\
\hline Comprehensive marketing ban & $24.9 \%$ & $23.9 \%$ & $22.6 \%$ & $21.2 \%$ & $19.9 \%$ \\
\hline High-intensity tobacco control campaign & $24.9 \%$ & $23.9 \%$ & $22.5 \%$ & $21.1 \%$ & $19.9 \%$ \\
\hline Strong health warnings & $24.9 \%$ & $24.7 \%$ & $23.3 \%$ & $21.9 \%$ & $20.6 \%$ \\
\hline Strong youth access enforcement & $24.9 \%$ & $24.8 \%$ & $22.9 \%$ & $20.9 \%$ & $19.2 \%$ \\
\hline Cessation treatment policies & $24.9 \%$ & $24.1 \%$ & $22.2 \%$ & $20.6 \%$ & $19.4 \%$ \\
\hline \multicolumn{6}{|l|}{ Combined policy effects } \\
\hline All above policies combined & $24.9 \%$ & $19.6 \%$ & $16.7 \%$ & $14.4 \%$ & $12.7 \%$ \\
\hline \multicolumn{6}{|l|}{$\%$ Change in smoking prevalence from status quo } \\
\hline \multicolumn{6}{|l|}{ Independent policy effects } \\
\hline Tax at $70 \%$ of retail price & & $-8.2 \%$ & $-10.1 \%$ & $-12.0 \%$ & $-13.7 \%$ \\
\hline Complete smoke-free air law & & $-4.3 \%$ & $-4.7 \%$ & $-5.2 \%$ & $-5.5 \%$ \\
\hline Comprehensive marketing ban & & $-3.5 \%$ & $-3.8 \%$ & $-4.2 \%$ & $-4.5 \%$ \\
\hline High-intensity tobacco control campaign & & $-3.5 \%$ & $-4.1 \%$ & $-4.5 \%$ & $-4.8 \%$ \\
\hline Strong health warnings & & $-0.2 \%$ & $-0.7 \%$ & $-0.9 \%$ & $-1.1 \%$ \\
\hline Strong youth access enforcement & & $0.0 \%$ & $-2.7 \%$ & $-5.5 \%$ & $-7.9 \%$ \\
\hline Cessation treatment policies & & $-2.6 \%$ & $-5.4 \%$ & $-6.7 \%$ & $-7.2 \%$ \\
\hline \multicolumn{6}{|l|}{ Combined policy effects } \\
\hline All above policies combined & & $-20.7 \%$ & $-28.9 \%$ & $-35.0 \%$ & $-39.3 \%$ \\
\hline
\end{tabular}

males and $19.4 \%$ in females by 2040. Smoking cessation treatment policies can avert 37566 SADs from 2010 to 2040 .

The final scenario projects the effect of implementing all MPOWER policies in 2011. By 2040, smoking preva- lence is projected to decrease to $14.0 \%$ in males and $12.7 \%$ in females. If the number of lives saved is totalled for all years between 2011 and 2040, then 89736 male and 55033 female deaths will be averted by 2040, or a total of 144769 deaths. 
Table 5 Total smoking-attributable deaths, SimSmoke the Netherlands, 2010-40.

\begin{tabular}{|c|c|c|c|c|c|}
\hline & 2010 & 2020 & 2030 & 2040 & Cumulative \\
\hline Status quo policies & 31888 & 34572 & 36227 & 33013 & 1042836 \\
\hline \multicolumn{6}{|l|}{ Independent policy effects } \\
\hline Tax at $70 \%$ of retail price & 31888 & 33742 & 34266 & 30864 & 1001997 \\
\hline Complete smoke-free air law & 31888 & 33992 & 34901 & 31691 & 1015557 \\
\hline Comprehensive marketing ban & 31888 & 34114 & 35202 & 32015 & 1021731 \\
\hline High-intensity tobacco control campaign & 31888 & 34095 & 35095 & 31841 & 1019543 \\
\hline Strong health warnings & 31888 & 34506 & 36031 & 32755 & 1038784 \\
\hline Strong youth access enforcement & 31888 & 34572 & 36217 & 32901 & 1042233 \\
\hline Cessation treatment policies & 31888 & 33933 & 34399 & 30722 & 1005269 \\
\hline \multicolumn{6}{|l|}{ Combined policy effects } \\
\hline All above policies combined & 31888 & 31715 & 29212 & 25307 & 898067 \\
\hline \multicolumn{6}{|c|}{ Absolute change in attributable deaths from status quo } \\
\hline \multicolumn{6}{|c|}{ Independent policy effects } \\
\hline Tax at $70 \%$ of retail price & & 830 & 1960 & 2149 & 40839 \\
\hline Complete smoke-free air law & & 580 & 1325 & 1322 & 27278 \\
\hline Comprehensive marketing ban & & 458 & 1025 & 998 & 21104 \\
\hline High-intensity tobacco control campaign & & 477 & 1132 & 1172 & 23293 \\
\hline Strong health warnings & & 66 & 196 & 259 & 4051 \\
\hline Strong youth access enforcement & & 0 & 10 & 112 & 603 \\
\hline Cessation treatment policies & & 639 & 1828 & 2291 & 37566 \\
\hline \multicolumn{6}{|l|}{ Combined policy effects } \\
\hline All above policies combined & & 2857 & 7015 & 7706 & 144769 \\
\hline
\end{tabular}

\section{DISCUSSION}

Using the SimSmoke model, we have presented a shortand long-term projection of the role of various tobacco control policies in reducing smoking prevalence and the number of smoking-attributable deaths. Due to the policies that were implemented in the Netherlands between 1996 and 2010, smoking prevalence was reduced by $16 \%$ and 7078 deaths were averted by the year 2010 . Almost half of these deaths (3098) were averted by the Dutch tax policy. Mass media campaigns (1217 deaths averted) and the cessation treatment policy (1113 deaths averted) also contributed. The low level of enforcement meant that the tobacco purchase ban for youth implemented in 2003 had negligible effects by 2010. However, the number of deaths averted by youth access as well as the other policies implemented between 1996 and 2010 continues to grow into the future. By 2040, 148000 deaths will be averted as a result of the policies already implemented.

While the Netherlands has implemented some tobacco control policies, there is still ample scope to strengthen tobacco control policies consistent with the FCTC. Smoking prevalence can be decreased by as much as $21 \%$ in the first year, with a $35 \%$ reduction in the next 20 years and almost $40 \%$ by 30 years. Because of the natural history of tobacco-related illnesses, reductions in smoking prevalence have a relatively small impact on the number of smoking-attributable deaths in the short term.
By 2040, however, 7706 deaths can be averted in that year alone with the stronger set of policies. Without effective tobacco control policies, almost a million lives will be lost to tobacco-related diseases between 2011 and 2040, of which 145000 can be saved with a comprehensive tobacco control package.

\section{Study limitations and strengths}

The smoking prevalence results depend first on estimates of the rates of smoking in 1996, and initiation, cessation and relapse rates. Reliable data were not available for relapse rates in the Netherlands and are, therefore, based on US rates. The estimated relative mortality risks for smokers are also based on studies from the United States [30] and other high-income countries [31], but the rates may differ in the Netherlands. We did not consider differences by socio-economic status, which may be expected to play an increasing role, nor did we consider the effect of immigration. Notably, the projections also do not include the additional deaths averted due to reductions in secondhand smoke exposure.

The policy modules depend on underlying assumptions, estimated parameters of the predicted effect on initiation and cessation and assumptions about the interdependence of policies. While we have not conducted sensitivity analysis for the current model, we have estimated confidence intervals in previous work [3,27]. For example, many studies, with relatively consistent 
results, have been conducted on the effects of tax policies, and we gauge that the effect sizes can vary by as much as $25 \%$ above or below our current estimate. There are also many studies of smoke-free legislation, with results somewhat less consistent than those of prices, but still falling into similar ranges. Studies on media campaigns and advertising bans provide a broad range of estimates, and effect sizes might be expected to vary by about $50 \%$ around the current model estimates. Studies on the overall effect of health warnings and cessation treatment policies on smoking prevalence are generally lacking, such that bounds are $100 \%$ (from zero to twice) the current estimates. Studies need to be conducted not only to gauge the initial effect of policies, but also to understand how those policies unfold over time, and depend on other policies in effect. Evidence indicates that public policies may be synergistic through their cumulative impact on social norms and their reinforcing effects on smokers' motivation to quit [27]. We have made the conservative assumption that the effects of each policy are a constant proportion of the smoking rate independent of other policies. However, the effects of health warnings, smoke-free legislation and cessation treatment policies are magnified in the model by the publicity of a well-funded media campaign. In turn, the effects of these other policies on the effect of a tobacco control campaign are intensified by the publicity that they generate.

Although the Netherlands has more extensive data than most European Union nations, it will be important to continue to collect detailed information on smoking prevalence by age and gender. In particular, smoking rates at early ages are needed, as well as information on the prevalence of former smokers, so that cessation rates can be estimated and quitting can be tracked. In addition, it would be useful to monitor quit attempt behaviours, the use of pharmacotherapies and quitlines, the involvement of physicians in advising patients to quit, cigarette prices of the prominent brands and the amount of smuggled cigarettes and compliance with marketing restrictions and smoke-free legislation. As this information is collected and monitored, the model can be adapted to reflect trends in smoking rates more accurately over time. Most importantly, improved data can be used to monitor and evaluate policies more effectively, so that policies can be modified and adapted in reaction to successes and failures.

\section{CONCLUSION}

The SimSmoke results highlight the relative contribution of numerous policies to reducing the tobacco health burden. We have shown that policies have already had an important impact in the Netherlands, but there is room for improvement. In complying with MPOWER FCTC recommendations (i.e. increasing the tax to $70 \%$ of price, strengthening health warnings, media campaigns and the provision of cessation treatment, as well as the complete prohibition and enforcement of smoking in public and workplaces, industry marketing and sales of tobacco to youth) the smoking rate is projected to fall by $40 \%$ in relative terms, with 145000 deaths averted by 2040. A large increase in taxes alone, or in the provision of cessation treatments, would reduce substantially the number of lives lost to smoking.

Implementation of the FCTC/MPOWER recommended policies could be expected to show similar or larger relative reductions in smoking prevalence in other countries which currently have weak policies. A substantial number of deaths can thereby be averted, especially in those countries which have a large smoking population.

\section{Declarations of interest}

None declared.

\section{Acknowledgements}

We would like to thank Daniel Rijckborst for assistance in collecting the data. We are grateful to the PPACTE Publication Committee, specifically Dr Colin Fischbacher and Professor Carlo La Vecchia, for the revision of the work presented in this paper. This is a deliverable within the PPACTE Project 'Pricing Policies and Control of Tobacco in Europe' and is funded partly by the European Commission through FP7 HEALTH-F2-2009-223323. The funder had no involvement in the study design, in the collection, analysis and interpretation of data, in the writing of the report and in the decision to submit the paper for publication.

\section{References}

1. Ezzati M., Lopez A. D. Estimates of global mortality attributable to smoking in 2000. Lancet 2003; 362: 847-52.

2. Hopkins D. P., Briss P. A., Ricard C. J., Husten C. G., CarandeKulis V. G., Fielding J. E. et al. Reviews of evidence regarding interventions to reduce tobacco use and exposure to environmental tobacco smoke. Am J Prev Med 2001; 20: 16-66.

3. Levy D. T., Gitchell J. G., Chaloupka F. The effects of tobacco control policies on smoking rates: a tobacco control scorecard. J Public Health Manag Pract 2004; 10: 338-51.

4. Hammond D. Health warning messages on tobacco products: a review. Tob Control 2011; Epub ahead of print 23 May 2011.

5. Reda A. A., Kaper J., Fikretler H., Severens J. L., van Schayck C. P. Healthcare financing systems for increasing the use of tobacco dependence treatment. Cochrane Database Syst Rev 2009; 2: CD004305.

6. World Health Organization (WHO). WHO report on the global tobacco epidemic: the MPOWER package. Geneva: WHO; 2008. 
7. World Health Organization (WHO). WHO report on the global tobacco epidemic, 2008: the MPOWER package. Geneva; WHO; 2010.

8. Hu T. W., Sung H. Y., Keeler T. E. Reducing cigarette consumption in California: tobacco taxes vs an anti-smoking media campaign. Am J Public Health 1995; 85: 1218-22.

9. Hu T. W., Sung H. Y., Keeler T. E. The state antismoking campaign and the industry response: the effects of advertising on cigarette consumption in California. Am Econ Rev 1995; 85: 85-90.

10. Farrelly M. C., Pechacek T. F., Chaloupka F. J. The impact of tobacco control program expenditures on aggregate cigarette sales: 1981-2000. J Health Econ 2003; 22: 843-59.

11. Homer J. B., Hirsch G. B. System dynamics modeling for public health: background and opportunities. Am J Public Health 2006; 96: 452-8.

12. Levy D. T., Bauer J. E., Lee H. R. Simulation modeling and tobacco control: creating more robust public health policies. Am J Public Health 2006; 96: 494-8.

13. Mendez D., Warner K. E., Courant P. N. Has smoking cessation ceased? Expected trends in the prevalence of smoking in the United States. Am J Epidemiol 1998; 148: 249-58.

14. Mendez D., Warner K. E. Adult cigarette smoking prevalence: declining as expected (not as desired). Am J Public Health 2004; 94: 251-2.

15. Tengs T. O., Osgood N. D., Chen L. L. The cost-effectiveness of intensive national school-based anti-tobacco education: results from the tobacco policy model. Prev Med 2001; 33: $558-70$.

16. Levy D. T., Friend K. A computer simulation model of mass media interventions directed at tobacco use. Prev Med 2001; 32: 284-94.

17. Ahmad S. Increasing excise taxes on cigarettes in California: a dynamic simulation of health and economic impacts. Prev Med 2005; 41: 276-83.

18. Ahmad S., Billimek J. Estimating the health impacts of tobacco harm reduction policies: a simulation modeling approach. Risk Anal 2005; 25: 801-12.

19. Levy D. T., Nikolayev N., Mumford E. A. Recent trends in smoking and the role of public policies: results from the SimSmoke tobacco control policy simulation model. Addiction 2005; 10: 1526-37.

20. Hoogenveen R. T., van Baal P. H., Boshuizen H. C., Feenstra T. L. Dynamic effects of smoking cessation on disease incidence, mortality and quality of life: the role of time since cessation. Cost Eff Resour Alloc 2008; 6: 1.

21. van Genugten M. L., Hoogenveen R. T., Mulder I., Smit H. A., Jansen J., de Hollander A. E. Future burden and costs of smoking-related disease in the Netherlands: a dynamic modeling approach. Value Health 2003; 6: 494-9.
22. Levy D. T., Chaloupka F., Gitchell J., Mendez D., Warner K. E. The use of simulation models for the surveillance, justification and understanding of tobacco control policies. Health Care Manag Sci 2002; 5: 113-20.

23. Levy D., Benjakul S., Ross H., Ritthiphakdee B. The role of tobacco control policies in reducing smoking and deaths in a middle income nation: results from the Thailand SimSmoke simulation model. Tob Control 2008; 17: 53-9.

24. Levy D., Cho S., Kim Y.-M., Park S., Suh M.-K., Kam S. An evaluation of the impact of tobacco control policies in Korea using the SimSmoke model: the unknown success story. Am J Public Health 2010; 100: 1267-73.

25. Levy D., Tworek C., Hahn E., Davis R. The Kentucky SimSmoke tobacco policy simulation model: reaching healthy people 2010 goals through policy change. South Med J 2008; 101: 503-7.

26. Levy D. T., Bauer J., Ross H., Powell L. The role of public policies in reducing smoking prevalence and deaths caused by smoking in Arizona: results from the Arizona tobacco policy simulation model. J Public Health Manag Pract 2007; 13: 59-67.

27. Levy D. T., Hyland A., Higbee C., Remer L., Compton C. The role of public policies in reducing smoking prevalence in California: results from the California tobacco policy simulation model. Health Policy 2007; 82: 153-66.

28. Joossens L., Raw M. The tobacco control scale 2010 in Europe. Paper presented at the Fifth European Conference on Tobacco or Health; Amsterdam, the Netherlands. 2011.

29. Willemsen M. C., Hoogenveen R. T., van der Lucht F. New smokers and quitters. Transitions in smoking status in a national population. Eur J Public Health 2002; 12: 136-8.

30. Thun M. J., Myers D. G., Day-Lally C., Namboodiri N. M., Calle E. E., Flanders W. D. et al. Age and the exposureresponse relationships between cigarette smoking and premature death in Cancer Prevention Study II. In: National Cancer Institute, editor. Changes in Cigarette Related Disease Risks and Their Implication for Prevention and Control. Smoking and Tobacco Control Monograph 8, NIH Publication no. 97-4213. Bethesda, MD: National Cancer Institute; 1997. p. 383-475.

31. Doll R., Peto R., Boreham J., Sutherland I. Mortality in relation to smoking: 50 years' observations on male British doctors. BMJ 2004; 328: 1519.

32. Levy D., Blackman K., Currie L., Clancy L., Willemsen M. The Netherlands SimSmoke: The Effect of Tobacco Control Policies on Smoking Prevalence and Tobacco Attributable Deaths in the Netherlands. 2011. Soon available at: http://www. PPACTE.eu. 